striatal activity in early childhood may account for the poor impulse control in normal young children who do have some behavioural characteristics akin to older children with ADHD.

In the 7 dysphasic children without ADHD, there was low flow to left prefrontal and central perisylvian region. Hypofunction of the left hemisphere is also suggested by the fact that 6 of the 15 language impaired children were left handed. In a study of cerebral flow distribution in 9 children with expressive language dysfunction Raynaud et $\mathbf{a l}^{16}$ found low flow to the left hemisphere. These indications of low neural activity in the left hemisphere are consistent with early reports on lateralised features in the EEG in dysphasia. ${ }^{17}$

In conclusion, we have shown that various developmental learning disabilities are associated with regional cerebral blood flow abnormalities as assessed with SPET. It may be that the phylogenetically recent linguistic functions are vulnerable to slight disturbances in regional cerebral activity whereas attention control, a primitive capacity important for survival, is protected from such changes.

Some of the patients in the control group were examined by Dr Sissel Vorstrup and Dr Karen Taudorf at the department of neurology, Rigshospitalet. The statistical analysis was carried out with the help of Dr Ole Pryds, department of paediatrics, Rigshospitalet.

\section{REFERENCES}

1. Hussey H. Study of the prevalence and therapy of the choreatic syndrome or hyperkinesis in rural Vermont. Acta Paedopsychiatr 1967; 34: $130-35$.

2. Rutter $M$, Tizard J, Whitmore K. Education, health and behavior: psychological and medical study of childhood development. New York: Wiley, 1980.
3. Caviness VS, Filipek PA, Kennedy DN. Magnetic resonance technology in human brain science: blueprint for a program based upon morphometry. Brain Dev 1989; 11: 1-14.

4. Duffy FH, Denckla MB, Sandini G. Dyslexia: differences in brain electrical activity by tomographic mapping. Ann Neurol 1980; 7: 412-20.

5. Goddard BA, Achery DM. Xe 133, Xe 127 and Xe 125 for lung investigations. A dosimetric comparison. $\mathcal{F}$ Nucl Med 1975; 16: $280-86$.

6. Lassen NA, Henriksen L, Paulson OB. Regional blood flow in stroke by ${ }^{133} \mathrm{Xe}$ inhalation and emission tomography. Stroke $1981 ; 12: 284-88$.

7. Lou HC, Henriksen L, Bruhn P. Focal cerebral hypoperfusion in children with dysphasia and/or attention deficit disorder. Arch Neurol 1984; 41: 825-29.

8. Rapin I. Children With Brain Dysfunction. International review of child neurology series. New York: Raven Press, 1982: 131-57.

9. Vorstrup S. Tomographic cerebral blood flow measurements in patients with ischaemic cerebrovascular disease. Acta Neurol Scand 1988; 77 (suppl): 15.

10. Lou HC, Henriksen L, Bruhn P, et al. Striatal dysfunction in attention deficit and hyperkinetic disorder. Arch Neurol 1989; 46: 48-57.

11. Iversen SD. Behavior after neostriatal lesions in animals. In: Divac I, Öberg RGE, eds. The neostriatum. Elmsford NY: Pergamon, 1977: 195-210.

12. Villablanca JR, el Olmstead CE. The striatum: a fine tuner of the brain Acta Neurobiol Exp 1982; L12: 227-99.

13. Luria AR. The frontal lobes and the regulation of behavior. In: Pribram KH, Luria AR, eds. Psychophysiology of the frontal lobes. Orlando Fla: Academic, 1973: 3-26.

14. Rolls ET. Initiation of movements In: Massion I, Paillard J, Schultz Wetal, eds. Neural coding of motor performance. New York: Springer, 1983, suppl 7: Experimental Brain Research, 97-113.

15. Lou HC, Henriksen L, Schreider S, et al. Redistribution of cerebral activity during childhood as assessed with SPET. Brain and Development (in press).

16. Raynaud C, Billard C, Tzonrig N, et al. Study of rCBF developmental dysphasic children at rest and during verbal stimulation. Cerebral Blood Flow Metab 1989; 9 (suppl 1): S323.

17. Annett $M$, Lee $D$, Ounsted $C$. Intellectual disabilities in relation to lateralised features in the EEG. Hemiplegic cerebral palsy in children and adults. London: Heinemann, 1961.

\title{
Cyclosporin toxicity at therapeutic blood levels and cytochrome P-450 IIIA
}

\author{
M. R. LUCEY J. C. KOLARS R. M. MERION \\ D. A. CAMPBELL M. ALDRICH P. B. WATKINS
}

\begin{abstract}
A 40-year-old male liver allograft recipient had neurological dysfunction and renal failure while his cyclosporin blood levels were in the therapeutic range; these features recurred on rechallenge. The hypothesis that this toxic effect might have resulted from abnormal metabolism of cyclosporin by liver cytochrome P-450 IIIA was investigated with the $\left[{ }^{14} \mathrm{C}\right]$ erythromycin breath test, which is a measure of this enzyme's activity. P-450 IIIA activity was decreased compared with that in controls, including other liver transplant recipients. Pretreatment with rifampicin, an inducer of P-450 IIIA, increased enzyme activity. After treatment with rifampicin the patient could be rechallenged with cyclosporin at a dose almost twice that which had previously been toxic. The patient died during a second transplantation and the microsomal content of P-450 IIIA was found to be low in the first transplant.
\end{abstract}

Lancet 1990; 335: 11-15.

\section{Introduction}

In general, the renal and neurological toxicity of cyclosporin is associated with high daily doses and high blood levels of the drug. ${ }^{1}$ However, cyclosporin can induce renal and neurological dysfunction in some patients while blood levels of parent drug are not elevated, ${ }^{1,2}$ which suggests that metabolites may be toxic. In most patients the major pathway of elimination of cyclosporin is hydroxylation to a metabolite, $M-17$; the blood concentration of $M-17$ can exceed that of the parent drug several fold. ${ }^{1}$ In rodents $\mathrm{M}-17$ is not nephrotoxic and, compared with cyclosporin, is rapidly eliminated in bile. ${ }^{3}$ It therefore seems unlikely that this metabolite alone is toxic. The liver enzyme responsible

ADDRESSES: Departments of Internal Medicine, Neurology and Surgery, University of Michigan Medical Center, Ann Arbor, Michigan, USA (M R. Lucey, FRCPI, J. C. Kolars, MD, R. M. Merion, MD, D. A. Campbell, MD, M. Aldrich, MD, P. B. Watkins, MD). Correspondence to Dr P. B. Watkins, Department of Internal Medicine, 6510 D MSRBI, University of Michigan Medical Center, $1150 \mathrm{~W}$ Medical Center Drive, Ann Arbor, Mich 48109, USA. 
for production of $\mathrm{M}-17$ is cytochrome P-450 IIIA, ${ }^{4}$ which appears to be the major phase I drug-metabolising enzyme inducible by rifampicin. ${ }^{5,6}$ The catalytic activity of this enzyme varies up to twenty-fold between patients ${ }^{7,8}$ and the rate of production of ${ }^{14} \mathrm{CO}_{2}$ in breath after intravenous injection of $\left[{ }^{14} \mathrm{C}\right]$ erythromycin is a useful measure of liver $\mathrm{P}-450$ IIIA activity in vivo. ${ }^{5}$

We describe a liver allograft recipient who had recurrent episodes of renal and neurological toxicity while blood levels of cyclosporin were maintained within the therapeutic range. We measured his in-vivo activity of P-450 IIIA by the erythromycin breath test compared with that of other patients, including liver transplant recipients, and we attempted to increase his P-450 IIIA activity by pretreatment with rifampicin

\section{Patients and methods}

Patients.-The erythromycin breath test was done in 5 male liver transplant recipients in addition to patient A. Patient A's history is presented in the Results section and details of the 5 other patients are shown in table I. The normal range for the breath test in adult males was established in 45 inpatients and outpatients. None were receiving any medications known to influence P-450 IIIA. 5.7,9 Details on 19 of these subjects have been reported..$^{5}$ All patients were studied according to protocols approved by the University of Michigan Committee for the Conduct of Human Research, which included the obtaining of informed consent.

Erythromycin breath test.-Briefly, $2 \mathrm{ml} 5 \%$ dextrose containing $\left[{ }^{14} \mathrm{C}\right] \mathrm{N}$-methylerythromycin $(0 \cdot 1 \mu \mathrm{mol}, 3 \mu \mathrm{Ci})$ was injected intravenously. Breath $\mathrm{CO}_{2}$ was collected $3,10,20,30,40$, 50 , and 60 min later by the patient exhaling into vials containing $4 \mathrm{ml}$ hyamine hydroxide/ethanol (1/1) and a trace of phenolphthalein. A change from blue to clear indicates that $2 \mathrm{mmol}$ $\mathrm{CO}_{2}$ has been trapped. The vials were capped and the specific activity of ${ }^{14} \mathrm{C}$ was measured by scintillation counting. The rate of ${ }^{14} \mathrm{C}$ exhalation was calculated from the endogenous output of $\mathrm{CO}_{2}$ $\left(5 \mathrm{mmol} / \mathrm{m}^{2}\right.$ body surface area). Breath test results were expressed as the percentage of administered radiolabel elimimated in $1 \mathrm{~h}$ (the area under the exhalation rate $v s$ time curve).

Immunochemistry of P-450 isozymes-Microsomes prepared from patient A's liver postmortem were subjected to quantitative immunoblotting. ${ }^{7}$ The blots were developed with a monoclonal antibody that selectively binds P-450 IIIA or antibodies that bind other human major liver cytochromes belonging to the P-450 II (HLx), P-450 IIE (HLj), P-450 IIC (P-450MP), and P-450 I (HLd) gene families. Purification of these proteins and the preparation of specific antibodies have been described..$^{7910}$ (Antibodies to $\mathrm{HLx}, \mathrm{HLj}, \mathrm{P}-450 \mathrm{MP}$, and HLd were gifts from Dr Steven Wrighton, Eli Lilly, Indianapolis.)

Cyclosporin assay.-Blood cyclosporin levels were measured by high-performance liquid chromatography. ${ }^{11}$ Unless expressly stated, all blood were drawn predose ("trough") at 0800 before morning administration of cyclosporin.

\section{Results}

A 40-year-old man with cryptogenic cirrhosis (patient A) received an orthotopic liver transplant in October, 1987. His preoperative serum creatinine was $106 \mu \mathrm{mol} / \mathrm{l}$. He had no history of renal or neurological disease. Fig 1 shows the clinical course during the first 120 days after transplantation. The immediate postoperative regimen consisted of methylprednisone, azathioprine and Minnesota antilymphoblast globulin. Antimicrobial and antifungal prophylaxis consisted of gentamicin, co-trimoxazole, cephalothin, and nystatin. Moderate hypertension was treated with labetalol. On the fourth postoperative day the patient was alert, lucid, and breathing without assistance.

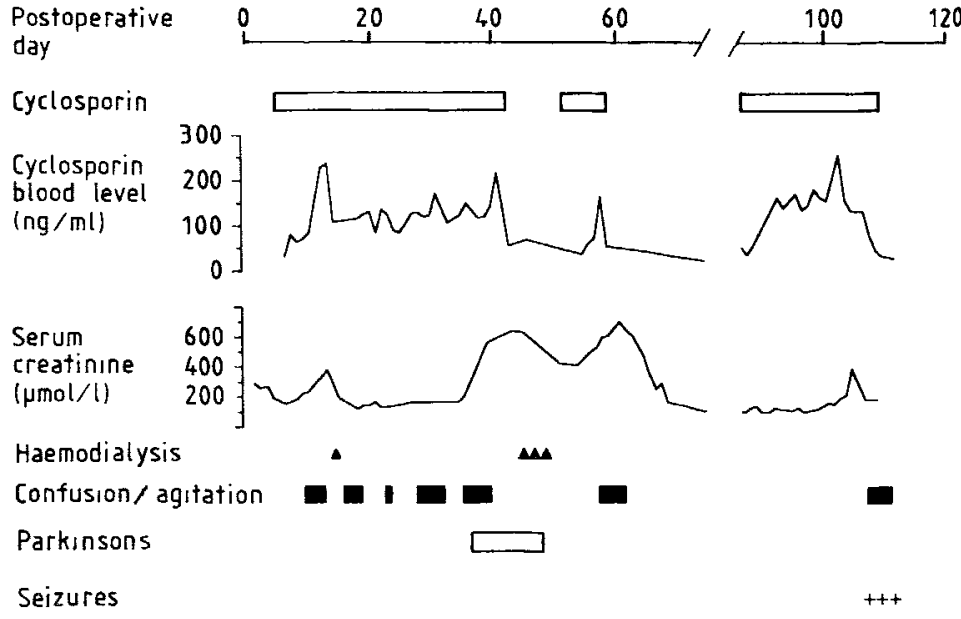

Fig 1 -Clinical course of patient A during first 120 days after orthotopic liver transplantation.

Cyclosporin, administered by nasogastric tube, was started on day 5 . Antilymphoblast globulin was withdrawn on day 8 and the patient was maintained on prednisone, azathioprine, and cyclosporin. Renal failure developed four times. The first occurrence, on day 14, followed a large volume thoracocentesis and was associated with oliguria and hyperkalaemia; thus prerenal azotaemia was a likely precipitating event. Haemodialysis was done once at this time and cyclosporin was not interrupted. All of the three subsequent episodes of renal failure did not have identifiable causes and were successfully managed by stopping cyclosporin. Haemodialysis was required during one of these episodes.

Patient A was intermittently confused and agitated throughout the first 120 postoperative days and these symptoms were worse during periods of reduced renal function (fig 1). Furthermore he had two other distinct neurological abnormalities. Firstly, from day 36 to 52, he had a parkinsonian-like syndrome with pill-rolling tremor, cog-wheel rigidity, and apathetic facies. These symptoms were initially attributed to haloperidol, which had been prescribed at $2 \mathrm{mg}$ every $4 \mathrm{~h}$ as required to treat agitation. Although haloperidol was stopped after 14 days and benzhexol $1 \mathrm{mg}$ twice daily was started, the symptoms persisted for a further 14 days until cyclosporin was withdrawn. Secondly, on day 108 , the patient had status epilepticus with recurrent grand mal seizures, which was managed by stopping cyclosporin, starting phenobarbitone and phenytoin, and by a short period of assisted ventilation. There were no clinical features of hypertensive encephalopathy and serum magnesium and calcium levels

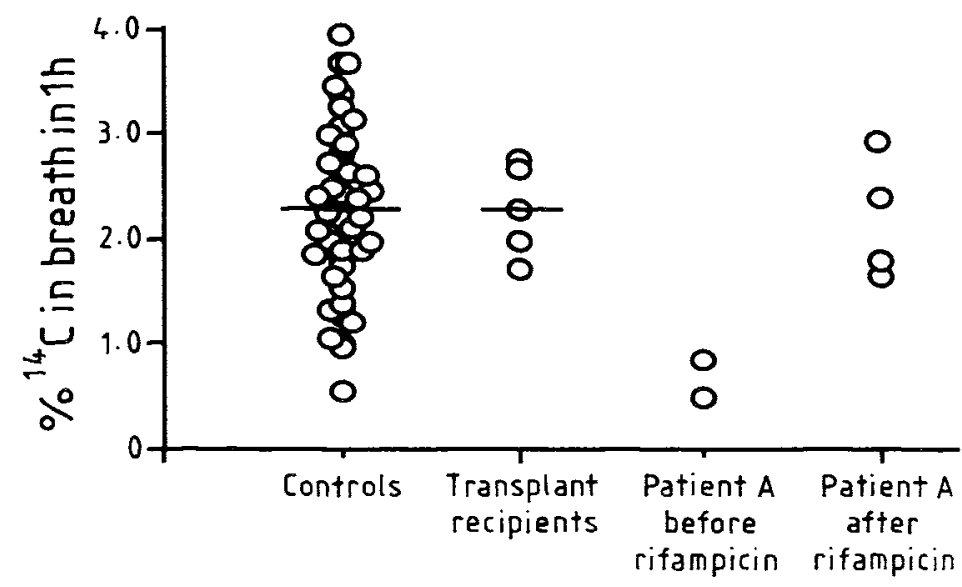

Fig 2-Erythromycin breath test results. 
TABLE I-CLINICAL DETAILS IN 5 LIVER TRANSPLANT RECIPIENTS AT TIME OF ERYTHROMYCIN BREATH TEST

\begin{tabular}{c|r|c|c|c|c|c|c}
\hline $\begin{array}{c}\text { Patient } \\
(\text { sex/age [yr] })\end{array}$ & $\begin{array}{c}\text { Days } \\
\text { post } \\
\text { Tpx }\end{array}$ & $\begin{array}{c}\text { Cyc in } \\
\text { blood } \\
(\mathrm{ng} / \mathrm{ml})\end{array}$ & $\begin{array}{c}\text { Creat } \\
(\mu \mathrm{mol} / \mathrm{I})\end{array}$ & $\begin{array}{c}\text { AST } \\
(\mathrm{IU} / \mathrm{I})\end{array}$ & $\begin{array}{c}\text { Total } \\
\text { bili } \\
(\mu \mathrm{mol} / \mathrm{l})\end{array}$ & $\begin{array}{c}\text { AP } \\
(\mathrm{IU} / \mathrm{I})\end{array}$ & $\begin{array}{c}\text { Breath } \\
\text { test } \\
(\%)\end{array}$ \\
\hline $1(\mathrm{M}, 33)$ & 82 & 188 & 123 & 16 & 10 & 109 & $1 \cdot 72$ \\
$2(\mathrm{M}, 45)$ & 194 & 143 & 106 & 91 & 19 & 526 & $2 \cdot 76$ \\
$3(\mathrm{M}, 39)$ & 137 & 134 & 70 & 10 & 7 & 83 & $2 \cdot 28$ \\
$4(\mathrm{M}, 31)$ & 300 & 87 & 97 & 30 & 9 & 187 & $2 \cdot 67$ \\
$5(\mathrm{M}, 26)$ & 67 & 72 & 62 & 47 & 102 & 691 & $2 \cdot 01$ \\
\hline
\end{tabular}

Tpx = transplantation; $\quad$ Cyc $=$ cyclosporin, Creat $=$ creatinine; $\quad A S T=$ aspartate aminotransferase; bili=bilirubin; and $A P=$ alkaline phosphatase.

All patients received prednisone, azathioprine, and cyclosporin. In addition, patient 1 received spirolactone and sucraflate; patient 2 received cimetidine and quinine; and patient 5 received ox bile, acyclovir, docusate sodium, and paracetamol.

were normal. Serial computerised axial tomographs of the head with and without contrast were normal. Electroencephalography during a seizure showed evidence of ictal activity but at other times showed a nonspecific pattern consistent with toxic or metabolic encephalopathy. The patient's serum cholesterol had been $141 \mathrm{mg} / \mathrm{dl}$ during the first week after transplantation.

Throughout the first 120 days, whole blood cyclosporin levels (fig 1) were within or below our target (therapeutic) range for liver transplant recipients $(100-300 \mathrm{ng} / \mathrm{ml})$. The typical daily dose of cyclosporin after clamping the $T$-tube was $320-480 \mathrm{mg}$ (4-6 mg/ $\mathrm{kg}$ ) and was adjusted according to blood levels. By day 111, 3 days after stopping cyclosporin, the patient was well, breathing without assistance, and lucid. He continued to take phenytoin until day 160 but had no further seizures. We concluded that in this patient cyclosporin treatment had resulted in renal and neurological dysfunction despite therapeutic blood levels of the drug. Because the seizures were life-threatening, continued treatment with cyclosporin was contraindicated; the patient received only azathioprine and prednisone for the next 3 months.

The erythromycin breath test was developed soon after patient A showed cyclosporin toxicity. In 45 male patients, the mean amount of radioactivity exhaled during the hour after injection with labelled erythromycin was $2.2 \%$ (fig 2 ). This value was similar in 5 liver transplant patients receiving various drugs, including cyclosporin (table I). We concluded that neither transplantation itself nor the administration of immunosuppressives significantly influenced the breath test values in these patients compared with control patients. To study whether P-450 IIIA was intact in patient $\mathrm{A}$, we administered the erythromycin breath test on days 169 and

TABLE II-CLINICAL DETAILS OF PATIENT A AT TIME OF ERYTHROMYCIN BREATH TEST

\begin{tabular}{l|c|c|c|c|c|c|c}
\hline $\begin{array}{c}\text { Days } \\
\text { post } \\
\text { Tpx }\end{array}$ & $\begin{array}{c}\text { Cyc } \\
\text { dose } \\
(\mathrm{mg} / \text { day })\end{array}$ & $\begin{array}{c}\text { Cyc } \\
\text { in blood } \\
(\mathrm{ng} / \mathrm{ml})\end{array}$ & $\begin{array}{c}\text { Creat } \\
(\mu \mathrm{mol} / \mathrm{I})\end{array}$ & $\begin{array}{c}\text { AST } \\
(\mathrm{IU} / \mathrm{I})\end{array}$ & $\begin{array}{c}\text { Total } \\
\text { bili } \\
(\mu \mathrm{mol} / \mathrm{I})\end{array}$ & $\begin{array}{c}\text { AP } \\
(\mathrm{IU} / \mathrm{I})\end{array}$ & $\begin{array}{c}\text { Breath } \\
\text { test } \\
(\%)\end{array}$ \\
\hline 169 & $\ldots$ & $\ldots$ & 88 & 248 & 19 & 1110 & $0 \cdot 86$ \\
202 & $\cdots$ & $\ldots$ & 90 & 93 & 54 & 965 & $0 \cdot 50$ \\
$205^{\star}$ & $\ldots$ & $\ldots$ & 114 & 83 & 54 & 865 & $2 \cdot 4$ \\
$211^{\star}$ & 160 & $\ldots$ & 106 & 105 & 156 & 920 & $2 \cdot 91$ \\
$214^{\star}$ & 160 & $<20$ & 106 & 188 & 226 & 975 & $1 \cdot 67$ \\
$220^{\star}$ & 640 & $<20$ & 90 & 228 & 374 & 925 & $1 \cdot 81$ \\
233 & $\cdots$ &.- & 290 & 206 & 730 & 2175 & $0 \cdot 28$ \\
\hline
\end{tabular}

* Includes rifampicin treatment. Other relevant medications: prednisone azathioprine, and labetalol on all days; acyclovir and co-trimoxazole on all test days except day 169; antithymocyte globulin and ox bile on days 214 and 220; and cephalothin on day 220.
BLOTS

PROTEIN

GENE

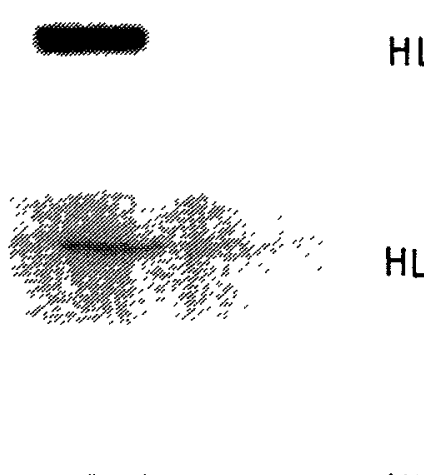

HLP

III

$H L x$

II

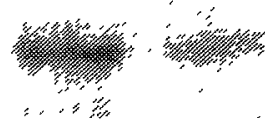

$P-450 M P$

IIC

wsym

HLd

$I$

\section{Patient Patient \\ $23 \quad A$}

Fig 3-Immunoblots from patient $A$ developed with antibodies that bind five different cytochrome P-450 isozymes.

Only regions of blots reacting with antibodies are shown. For comparison, microsomes prepared from another patient (no 23) were analysed on same blots. Microsomes from this patient have been previously shown to have typical concentrations of each protein assayed.'

202 after transplantation. Each time the eliminated radiolabel was low compared with the two reference groups of men (fig 2). It was unlikely that this was due to general liver dysfunction because on these occasions conventional liver integrity tests were only mildly abnormal (table II) and similar to those seen in the other liver transplant recipients (table I). Therefore the donor liver was probably deficient in P-450 IIIA activity. We postulated that this defect may have resulted in aberrant cyclosporin metabolism and accumulation of a toxic metabolite. Next we investigated whether patient A's breath test could be increased by oral pretreatment with rifampicin $600 \mathrm{mg}$ per day. There was a dramatic rise in the breath test result after just 2 days (fig 2).

Patient A had progressive cholestasis on days 200-210 and liver biopsy consistent with chronic rejection and intrahepatic venous congestion. The clinical features of chronic rejection and cholestasis worsened despite use of the anti-T lymphocyte monoclonal antibody OKT3. We decided to re-start cyclosporin, which provided an opportunity to test our hypothesis that deficiency in P-450 III A had resulted in accumulation of a toxic metabolite. Rifampicin was administered daily and the erythromycin breath test was done twice a week. Initially rifampicin $600 \mathrm{mg}$ was given orally and then $300 \mathrm{mg}$ after 3 days. This dose maintained a breath test result greater than $1.5 \%$ (table II). The breath test was done before the daily dose of cyclosporin, which was administered at 0800 ; rifampicin was given at 1500 . 
Neither renal nor neurological dysfunction developed while the patient was receiving cyclosporin plus rifampicin. However, as shown in table II, therapeutic blood levels of cyclosporin were never achieved during the 10 day course of treatment (days 211-220). Because absorption of cyclosporin depends in part on intraluminal bile, we assumed that the patient's progressive cholestasis had caused poor absorption. However, from day 213 onward, cyclosporin was administered with ox bile. Although the cyclosporin dose of $8 \mathrm{mg} / \mathrm{kg}$ per day was almost twice that which resulted in toxicity during the first 100 postoperative days, the drug was virtually undetectable in blood, even during the first $6 \mathrm{~h}$ after the oral dose (data not shown). The reason for the poor systemic availability was obscure. The patient continued to eat meals and did not have diarrhoea during this period. Cyclosporin and rifampicin were stopped on day 222 because of a continued decline in hepatic function. The patient subsequently had hepatic failure with grade 3 encephalopathy. By day 235, the erythromycin breath test result was once again low (table II).

On day 236 the patient underwent an attempted second transplant during which he died; liver was obtained about $30 \mathrm{~min}$ later. The concentration of each $\mathrm{P}-450$ protein assayed, including P-450 IIIA, was low compared with that in microsomes prepared from a representative "normal" patient (fig 3). However, the content of P-450MP was relatively preserved in patient A's liver.

\section{Discussion}

We have presented a liver transplant recipient who had repeated episodes of renal failure and neurological disturbances while receiving cyclosporin. Although these events were not related to elevated blood levels of cyclosporin, we attribute them to this drug because other causes, such as significant systemic hypertension or electrolyte abnormalities, were not present. Furthermore, on three separate occasions, toxicity promptly resolved when cyclosporin was stopped.

There is an association in liver transplant recipients between cyclosporin toxicity and blood cholesterol levels lower than $120 \mathrm{mg} / \mathrm{dl}$ in the first week after transplantation. ${ }^{2}$ Since cyclosporin circulates in blood largely bound to lipoproteins, low cholesterol levels may be associated with a larger proportion of unbound, biologically active drug. Our patient's cholesterol was $141 \mathrm{mg} / \mathrm{dl}$ at the time he first manifested toxicity and therefore a significant increase in unbound cyclosporin seems unlikely. However, we twice demonstrated that this patient had low P-450 IIIA activity as assessed by the erythomycin breath test. Cytochrome P-450 IIIA appears to catalyse the major route of metabolism of cyclosporin in most patients. ${ }^{4,6}$ The liver received by our patient may have been deficient in P-450 IIIA activity because: (1) low P-450 IIIA activity was not a consequence of liver transplantation since 5 male transplant recipents had breath test results that were similar to those in 45 control patients; (2) there were no serological or clinical indications of general liver dysfunction in patient $A$ at the time of his initial breath tests; (3) we were able to increase significantly P-450 IIIA activity by treating the patient with rifampicin; and (4) a defect in P-450 IIIA was supported by our post-mortem examination of patient A's liver. Our observation that the concentrations of all five cytochrome $\mathrm{P}-450$ isozymes were low in patient A's liver microsomes was expected, given the severe general hepatic dysfunction at the time of death. However, P-450MP was relatively preserved in these microsomes (fig 3). Taken together, the observations suggest that the donor liver received by patient A had a defect, presumably genetic, in $\mathrm{P}-450$ IIIA protein or regulation.

Inherited defects in liver cytochromes $\mathrm{P}-450$ are common. ${ }^{12}$ The best studied example is deficiency in cytochrome P-450 IID activity, which results in decreased ability to hydroxylate debrisoquine and many other drugs normally. ${ }^{13,14}$ Deficient P-450 IID activity is found in up to 1 in 10 patients and is inherited as an autosomal recessive trait. This selective defect can have adverse pharmacological consequences. For example, poor metabolisers of debrisoquine are at increased risk of liver injury due to perhexiline, presumably because P-450 IID is involved in detoxification and/or elimination of this drug. ${ }^{15}$ It is likely that interpatient differences in response to several drugs result in part from inherited defects in individual cytochromes P-450. ${ }^{12}$

P-450 IIIA cytochromes are highly conserved in mammalian species. They are the major drug metabolising enzymes in man, accounting for up to $25 \%$ of the total cytochrome P-450 in human liver. ${ }^{9}$ P-450 IIIA may be especially active in detoxification because rodents pretreated with inducers of P-450 IIIA are resistant to the toxic effects of many drugs, ${ }^{16}$ and appear resistant to hepatic malignancies induced by dimethylnitrosamine. ${ }^{17}$

We do not know why a deficiency of P-450 IIIA activity may have contributed to cyclosporin toxicity in our patient. At least 29 metabolites of cyclosporin have been identified in man, $^{1}$ making it likely that multiple enzymes can metabolise this drug. Deficiency in the P-450 IIIA mediated pathway might "shunt" cyclosporin to alternative pathways that may lead to toxic metabolites. Alternatively, since $P-450$ IIIA appears to catalyse reactions that produce at least two other major metabolites of cyclosporin, ${ }^{4}$ P-450 IIIA may detoxify or help eliminate a toxic metabolite generated by other enzymes: deficiency in P-450 IIIA activity would therefore result in accumulation of the toxic metabolite.

When clinical circumstances indicated that further use of cyclosporin might save patient A's liver graft, we hoped to avoid toxicity by manipulating expression of cytochrome P-450 IIIA activity with rifampicin. We were successful in maintaining normal erythromycin breath test results and in avoiding renal and neurological toxicity. However, we could not achieve therapeutic blood levels of cyclosporin nor could we control allograft rejection. The reason why systemic availability of oral cyclosporin was poor in our patient is unclear. Because cyclosporin is highly lipophilic and requires bile for its absorption, ${ }^{18}$ our patient's severe cholestasis may have prevented absorption. However, the patient had good oral bioavailability of cyclosporin earlier in his postoperative course when his bile was drained externally through a $\mathrm{T}$-tube and refed via a nasogastric cannula. Moreover, systemic availability was not improved when cyclosporin was administered with ox bile.

An alternative or additional explanation is that rifampicin may have induced P-450 IIIA activity in the enterocytes lining the gut. P-450 IIIA is present and inducible in enterocytes ${ }^{19}$ and, at least in rats, intestinal P-450 IIIA can metabolise cyclosporin. ${ }^{20}$ Therefore significant metabolism of cyclosporin may occur within the gut. ${ }^{21} \mathrm{We}$ believe that as we increased the donor liver P-450 IIIA activity with rifampicin, we also significantly induced the patient's intestinal P-450 IIIA, thus limiting the systemic availability 
of oral cyclosporin. Our next plan had been to administer cyclosporin intravenously. However, concern that cholestasis was due in part to either rifampicin or cyclosporin forced us to abandon concomitant treatment with these agents.

Conney ${ }^{22}$ has predicted that "cytochrome P-450 doctors" will create a new subspecialty in the future. Knowledge of inherited defects in cytochromes $\mathrm{P}-450$ has already proved useful in establishing appropriate dosing of some drugs. ${ }^{23}$ Our study is the first attempt in man to induce a specific cytochrome P-450 in pursuit of a defined, therapeutic effect. As knowledge about the induction of human liver P-450 isozymes increases, these manoeuvres may become commonplace in clinical practice.

We thank Ms Pam Evans for typing the manuscript and Ms Elizabeth Wilson for preparing the figures. This work was supported by grant GM-38149 from the National Institutes of Health. P. B. W. receives a Veterans Administration research associate award.

\section{REFERENCES}

1. Kahan BD, Grevel J. Optimization of cyclosporine therapy in rena transplantation by a pharmacokinetic strategy. Transplantation 1988 ; 46: 631-44.

2. de Groen PC, Aksanut AJ, Rakela J, Forbes GS, Krom RAF. Central nervous system toxicity after liver transplantation: the role of cyclosporine and cholesterol. $N$ Engl I Med 1987; 317: 861-66.

3. Ryffel B, Foxwell BMJ, Mihatsch MJ, Donatsch P, Maurer G. Metabolites of cyclosporine. Transplant Proc 1988; 20: 575-84.

4. Kronback T, Fischer V, Meyer UA. Cyclosporine metabolism in human liver: identification of a cytochrome P-450 III gene family as the major cyclosporine-metabolizing enzyme explains interactions of cyclosporine with other drugs. Clin Pharmacol Ther 1988; 43: 630-35.

5. Watkins PB, Murray SA, Winkelman LG, Heuman DM, Wrighton SA, Guzelian PS. Erythromycin breath test as an assay of glucocorticoid inducible liver cytochromes $\mathrm{P}-450$ : studies in rats and patients. $\mathcal{F}$ Clin Invest 1989; 83: 688-97.

6. Combalbert J, Fabre I, Fabre G, et al. Metabolism of cyclosporin A IV: purification and identification of the rifampicin-inducible human liver cytochrome P-450 (cyclosporin A oxidase) as a product of P450IIIA gene subfamily. Drug Metab Dis 1988; 17: 197-207.

7. Wrighton SA, Thomas PE, Willis $P$, et al. Purification of a human liver cytochrome P -450 immunochemically related to several cytochromes P-450 purified from untreated rats. $\mathcal{F}$ Clin Invest 1987; 80: 1017-22.

8. Guengerich FP, Martin MV, Beaunne $\mathrm{PH}$, Kremers $\mathrm{P}$, Wolff $\mathrm{T}$, Waxman DJ. Characterization of rat and human liver microsoma cytochrome $\mathrm{P}-450$ forms involved in nifedipine oxidation, a prototype for genetic polymorphism in oxidative drug metabolism. $\mathcal{F}$ Biol Chem 1986; 261: 5051-60.

9. Watkins $\mathrm{PB}$, Wrighton $\mathrm{SA}$, Maurel $\mathrm{P}$, et al. Identification of an inducible form of cytochrome P-450 in human liver. Proc Natl Acad Sci USA $1985 ; 82: 6310-14$

10. Watkins PB, Murray SA, Thomas PE, Wrighton SA. The distribution of cytochromes $\mathrm{P}-450$, cytochromes $\mathrm{B} 5$, and NADPH reductase in an entire human liver. Biochem Pharmacol (in press)

11. Annesley T, Matz K, Balogh L, Clayton L, Giacherio D. Ligand chromatographic analysis of cyclosporine with use of a micropore column and small sample size. Clin Chem 1986; 32: 1407-09.

12. Jacquz E, Hall SD, Branch RA. Genetically determined polymorphisms in drug oxidation. Hepatology 1986; 6: 1020-32.

13. Mahgoub A, Idle JR, Dring LG, Lancaster R, Smith RL. Polymorphic hydroxylation of debrisoquine in man. Lancet 1977; ii: 584-86.

14. Gonzales FJ, Skoda RC, Kimura S, et al. Characterization of the common genetic defect in humans deficient in debrisoquine metabolism. Nature 1988; 331: 442-46.

15. Morgan MY, Reshef R, Shah RR, Oates NS, Smith RL, Sherlock S. Impaired oxidation of debrisoquine in patients with perhexiline liver injury. Gut 1984; 25: 1057-64.

16. Selye H. Hormones and resistance. F Pharm Sci 1971; 60: 1-28

17. Argus MF, Hoch-ligeti C, Arcos JC, Conney AH. Differential effects of beta-naphthoflavone and pregnenolone-16x-carbonitrile on dimethylnitrosamine-induced hepatocarcinogenesis. F Natl Cancer Inst $1978 ; 61: 441-49$.

18. Naoumov NV, Tredger JM, Steward CM, et al. Cyclosporin A pharmacokinetics in liver transplant recipients in relation to biliary T-tube clamping and liver dysfunction. Gut 1989; 30: 391-96.
19. Watkins PB, Wrighton SA, Scheut EG, Molowa DT, Guzelian PS Identification of glucocorticoid-inducible cytochromes $\mathrm{P}-450$ in the intestinal mucosa of rats and man. $\mathcal{F}$ Clin Invest 1987; 80: 1029-36.

20. Kolars JC, Duell EA, Benedict PE, et al. P-450 III metabolizes cyclosporin $\mathrm{A}$ in intestinal mucosa: observations in a novel rat model. Clin Res 1989; 37: 933A

21. Sawchuck RJ, Awni WM. Absorption of cyclosporin from rabbit small intestine in situ. F Pharm Sci 1986; 75: 1151-56.

22. Conney AH. Induction of microsomal cytochrome P-450 enzymes: the first Bernard B. Brodie lecture at Pennsylvania State University. Life Sci 1986; 39: 2493-518.

23. Brosen K, Gram LF. Clinical significance of the sparteine/debrisoquine oxidation polymorphism. Eur F Clin Pharmacol 1989; 36: 537-47.

\section{Detection of sickle cell anaemia mutation by colour DNA amplification}

\author{
FARID F. CHEHAB YUET WAI KAN
}

A fluorescence assay to detect the mutation in sickle cell anaemia has been developed. Oligonucleotides homologous to the normal or the mutant DNA sequence are labelled with fluorescein and rhodamine, respectively, and used to prime the polymerase chain reaction. Amplified DNA products with the normal sequence fluoresce green, whereas those with the mutant sequence fluoresce red; heterozygous (AS) DNA fluoresces yellow. The results can be read by eye and the procedure could be automated.

Lancet 1990; 335: 15-17.

\section{Introduction}

For many years, postnatal diagnosis of sickle cell anaemia was routinely accomplished by haemoglobin electrophoresis. More recently, techniques that permit prenatal detection of the sickle gene have been developed: at first, these techniques required fetal blood, ${ }^{1}$ but recombinant DNA technology has enabled analysis of amniocytes or chorionic villi acquired in early pregnancy. DNA analysis techniques have evolved from indirect linkage analysis ${ }^{2}$ to direct detection with restriction enzymes ${ }^{3,4}$ or oligonucleotide probes. ${ }^{5}$ DNA amplification by the polymerase chain reaction $(\mathrm{PCR})^{6}$ has made possible the rapid identification of DNA sequence variations in the human genome, and is a rapid, non-radioactive way to detect these variations. After PCR, mutations can be detected by various methods such as restriction enzyme analysis,? dot-blot hybridisation, ${ }^{8}$ chemical cleavage, ${ }^{9,10}$ or denaturation and gel electrophoresis ${ }^{11}$ - but these techniques may not be generally available. We have described a detection method by which fluorophores are

ADDRESSES: Applied Biosystems Inc, Foster City, California (F. F. Chehab, PhD); and Departments of Laboratory Medicine and Medicine, and Howard Hughes Medical Institute. University of California, San Francisco, California, USA (Prof Y. W. Kan, FRS) Correspondence to Dr F F. Chehab, Department of Human Genetics M4, Cetus Corporation, 1400 53rd Street, Emeryville, CA 94608, USA 